\title{
X-ray synchrotron computed microtomography $(\mu$-CT) analysis of the pore network of hydrothermal vent chimneys from the East Pacific Rise
}

\author{
AARON CLAEYS* 1, SIMONE PUJATTI1, \\ BENJAMIN M. TUTOLO1 \\ 1 University of Calgary, 2500 University Dr. NW, Calgary, \\ AB, Canada, T2N 1N4 | aaron.claeys@ucalgary.ca
}

Hydrothermal vent systems occur where hot hydrothermal vent fluid $\left(>350{ }^{\circ} \mathrm{C}\right)$ mixes with cold seawater $\left(\sim 2{ }^{\circ} \mathrm{C}\right)$ at seafloor spreading centres, precipitating minerals at the seawater- hydrothermal fluid interface. Hydrothermal vents provide a habitable environment for many chemolithoautotrophs by providing a substrate for colonization shielded from the uninhabitable temperatures found in the hydrothermal plume. As dissolved gases travel across a vent wall, they form a chemical gradient from the relatively high concentrations within the vent fluids to the exceptionally low concentrations in the nearby seawater. To investigate this process, chimney samples, in situ fluid chemistry and venting temperature were acquired from the East Pacific Rise at $9^{\circ} 50^{\prime} \mathrm{N}$ during a sequence of dives with DSV Alvin from the Bio9, Tica and $\mathrm{P}$ vents. Chimneys were subsampled and analysed by means of high-resolution synchrotron x-ray micro-computed tomography ( $\mu-\mathrm{CT})$ which allowed us to measure porosity, pore connectivity and simulate the permeability of chimney walls samples. The results were subsequently correlated to EPMA mineral identification and geochemical modelling of mineral saturation states. Coupled interpretation of porosity and permeability values with the observation of the dominant mineralogy in each vent allowed us to determine transport regimes and precipitation mechanisms at each vent chimney. Together, the results provide vital constraints on ongoing attempts to model the transport of solutes across vent chimney walls, the dominant transport mechanisms present in hydrothermal vent systems and the utilisation of nutrients by hyperthermophilic chemolithoautotrophs for metabolism. 